\title{
A literatura e a dichtung na constituição do imaginário espírita e o contexto da pandemia de covid-19
}

\author{
The literatur and dichtung in the constitution \\ of the spiritist imaginary and the context of the \\ pandemic of covid-19
}

\section{La literatura y dichtung em la constitución del imaginario espiritista y el contexto de la pandemia del covid-19}

\section{Gismair Martins Teixeira}

\begin{abstract}
RESUMO
O presente estudo traz uma abordagem em torno da constituição do imaginário espírita no tempo e no espaço através do conceito alemão de literatura apresentado pelo crítico literário Antonio Candido. Apresenta também como esse imaginário, a partir da conceituação do pesquisador francês Gilbert Durand para esse campo de estudos, dialoga com o contexto atual da pandemia de Covid-19 que assola a humanidade neste ano de 2020. O conceito de literatura da cultura alemã se apresenta mais abrangente do que aquele que é adotado pela cultura brasileira, que não possui terminologia própria para distinguir toda e qualquer produção textual daquelas de natureza artística. Este trabalho articula o conceito literário alemão, projetando-o sobre um recorte historiográfico do espiritismo franco-brasileiro, numa perspectiva de como essa interação se reflete no atual contexto pandêmico da Covid-19.

Palavras-chave: Literatura; dichtung; imaginário; espiritismo; Covid-19.
\end{abstract}

\begin{abstract}
The present study brings an approach about the spiritist imaginary constitution in time and space through the German concept of literature presented by the literary critic Antonio Candido. It also presents how this imaginary, from the conception of the French researcher Gilbert Durand for this field of studies, dialogues with the current context of the Covid-19 pandemic that plagues the population in the present year of 2020. The concept of literature of German culture is more comprehensive than that adopted by Brazilian culture, which does not have its own terminology to distinguish any textual production from those of an artistic nature. This work articulates the German literary concept, projects it on a historiographical perspective of French-Brazilian spiritism in a perspective of how this interaction is shown in the current context of Covid-19.
\end{abstract}

Keywords: Literatur; dichtung; imaginary; spiritism; Covid-19.

\section{RESUMEN}

El presente estudio aborda la constitución del imaginario espírita en el tiempo y el espacio a través del concepto alemán de literatura presentado por el crítico literario Antonio Candido. También presenta cómo este imaginario, basado en el concepto del investigador francés Gilbert Durand para este campo de estudios, dialoga con el contexto actual de la 
pandemia Covid-19 que castiga a la humanidad en este año de 2020. Se presenta el concepto de literatura cultural alemana más amplio que el adoptado por la cultura brasileña, que no tiene una terminología propia para distinguir ninguna producción textual de las de carácter artístico. Este trabajo articula el concepto literario alemán, proyectándolo en una sección historiográfica del espiritismo franco-brasileño, en una perspectiva de cómo esta interacción se refleja en el actual contexto pandémico del Covid-19.

Palabras clave: Literatura; dichtung; imaginario; espiritismo; Covid-19.

\section{Introdução}

A linguística e a semiótica enfeixam praticamente toda a possibilidade comunicacional que o ser humano pôde desenvolver ao longo de sua história. A escrita e os signos de todos os matizes possibilitaram o desenvolvimento cultural numa amplitude colossal que se encontra longe de ser esgotada. Ajustando as lentes sobre a produção escrita propriamente considerada, observa-se com o linguista russo, Roman Jakobson, que a linguagem escrita possui funções variadas que, apesar de suas características particulares, interpenetram-se (JAKOBSON, 2003, p. 13).

$\mathrm{Na}$ tradição cultural brasileira, o termo "literatura" é utilizado numa perspectiva lato sensu. Na tradição germânica, no entanto, literatur e dichtung, conforme esclarece Antonio Candido (1996, p. 12), um dos ícones da intelectualidade brasileira, representam uma perspectiva stricto sensu que desce a especificidades que no caso brasileiro exige a presença do predicativo para que se saiba a que tipo de literatura se refere.

Neste artigo utilizamos a conceituação alemã, que se mostra bastante operacional para o objetivo a que nos propomos aqui: abordar a constituição do imaginário espírita num recorte literário abrangente e sua incidência no contexto pandêmico do Covid-19 mediado pela institucionalidade do movimento espiritista brasileiro. $\mathrm{O}$ conceito de imaginário adotado neste estudo é o apresentado pelo pesquisador francês, Gilbert Durand (2012, p. 18). Além dos autores mencionados, fundamentam este estudo a pesquisa sobre espiritismo do sociólogo da Universidade de São Paulo, Reginaldo Prandi, assim como o trabalhado da historiadora Mary del Priore sobre a história dessa doutrina surgida na França na segunda metade do século XIX.

\section{Os ecos da dichtung na constituição do imaginário espírita}

Em $O$ estudo analítico do poema, obra elaborada a partir de material composto para um curso na Universidade de São Paulo sobre a análise da poesia, o crítico de literatura Antonio Candido, um dos mais respeitados nomes da intelectualidade brasileira no campo dos estudos literários, estabelece impor- 
tante distinção para a área geral das letras. Suas observações se vinculam à didática própria de uma das mais significativas literaturas da cultura universal, a alemã. Segundo Candido, os germânicos distinguem nitidamente entre a produção escrita que se circunscreve à criação artística e todas as demais formas de texto. Registra Candido (1996, p. 12): “Literatur em alemão é o conjunto de tudo o que se escreveu sobre qualquer assunto. Dichtung é que significa o que se escreveu em estilo literário e com intuito criador".

Assinala, ainda, o autor de $O$ estudo analítico do poema, que a ausência dessa distinção já levou à confusão importantes nomes da intelectualidade literária brasileira no passado como, por exemplo, Silvio Romero (CANDIDO, 1996, p. 12). No presente estudo, utilizaremos a conceituação germânica para discorrermos sobre a construção do imaginário espírita e como sua textualidade se faz presente através do movimento de religiosidade que segue as diretrizes textuais estabelecidas por Allan Kardec na construção do imaginário espírita.

Dichtung e literatur se configuram como duas margens de caudaloso rio. Ambas funcionam como importantes elementos dialógicos contentores do imaginário espiritista. Neste trabalho, ambos os conceitos literários funcionarão, ainda, como elementos desencadeadores de uma apreciação em torno da forma como um recorte específico da institucionalidade religiosa espírita tem se comportado diante do catastrófico cenário pandêmico desencadeado pela presença do vírus da Covid-19. De início, vamos nos deter sobre aspectos da dichtung presentes no contexto constitutivo do espiritismo francês.

A partir do ano de 1853 e até o ano de 1855, o escritor francês Victor Hugo se manteve distante de seu país natal. Suas desavenças políticas com o regime de Napoleão III o levaram à ilha de Jersey, encravada entre a Inglaterra e a França, onde teve início não somente o exílio político que marcaria a biografia do importante romancista das letras francesas, mas também a sua iniciação em uma peculiar aventura de natureza espiritual. Esse período foi registrado em atas que preencheram quatro cadernos, sendo que somente dois chegaram até os dias atuais, perdendo-se os demais por conta da displicência de herdeiros e amigos que não tiveram o necessário cuidado com a memória hugoana desse período em que o romancista esteve diretamente envolvido com o fenômeno que influenciaria a sua produção literária (BOIVIN, 2018, p. 531).

O fenômeno a que o autor do romance Os miseráveis se empenhou no tempo documentado da ilha de Jersey recebeu a denominação de mesas girantes, variando também em expressões homológicas como mesas volantes, a dança das mesas e outras denominações congêneres, conforme registra Mary del Priore em $A$ história do sobrenatural e do espiritismo (2014, p. 37). Em relação 
à França, teve ele início do outro lado do Atlântico, em 1847, no condado de Hydesville, Estado de Nova York, nos Estados Unidos, com os acontecimentos que se passaram no lar da família Fox, quando estranhos barulhos que percutiam por toda a residência chamou a atenção para algo de cunho sobrenatural, conforme registra o pesquisador Reginaldo Prandi (2012, p. 22).

Com o tempo se instituiu toda uma sematologia que permitiu a comunicação entre a fonte do estranho ruído, que se revelou um caixeiro viajante morto naquela residência por um antigo morador, e a família dos Fox, cujas irmãs Katherine (Kate) e Margaret (Maggie) serviam involuntariamente, de início, como intermediárias do processo através da expansão de um tipo peculiar de energia que dali em diante receberia nomenclatura diversa, consagrando-se a forma semântica mais popular conhecida como "mediunidade" (PRIORE, 2014, p. 28).

Quem dá notícia desse marco inicial é outro nome ligado à arte literária, Arthur Conan Doyle, consagrado no contexto literário universal como o criador da personagem investigativa Sherlock Holmes. Conan Doyle se tornaria um dos mais ardorosos divulgadores do espiritualismo anglo-saxão, que apresenta singulares relações de proximidades com o espiritismo kardequiano (PRANDI, 2012, p. 33), cuja diferenciação a taxonomia apresentada por Allan Kardec estabelecerá na distinção entre o espiritismo e o espiritualismo.

É neste contexto espiritual do Oitocentismo, portanto, que Victor Hugo realizará experiências de comunicação com o suposto mundo do além através de uma mesinha de três pés que se movimentará em direção ao alfabeto ao influxo de uma suposta energia mediúnica oriunda de seu filho, Charles Hugo, cunhando extensas mensagens atribuídas a espíritos diversos, dentre os quais alguns de seus pares literários do panteão do cânone da literatura universal de diversos tempos e lugares (BOIVIN, 2018, p. 175). Os experimentos de Hugo tinham, pois, o antecedente das irmãs Fox, cujo ethos se espraiou por diversas regiões europeias (PRIORE, 2014, p. 37).

Neste zeitgeist característico do Oitocentismo, o pedagogo pestalozziano Hipolyte León Denizard Rivail entrará em contato com as insólitas ocorrências de natureza espiritual. De início, manifestará descrença ante a possibilidade de que uma mesa possa responder a perguntas, uma vez que elas deveriam ser dotadas de nervos e cérebro para que isso fosse possível (KARDEC, 2002, p. 390). Instado a participar de reuniões em que a mesa respondia aos consulentes, muniu-se o professor Rivail de caderno com perguntas específicas sobre as mais diversificadas ramificações do saber, submetendo-as aos supostos seres de além-túmulo. 
O resultado inicial dessa atividade de Denizard Rivail foi publicado em 18 de abril de 1857 com o insólito título de O livro dos espíritos. Constituía-se, em sua primeira edição, de 501 perguntas, que a partir de sua segunda edição, em 18 de março de 1860, foram ampliadas para 1.019 questionamentos submetidos às inteligências extracorpóreas. Em seguida a O livro dos espíritos, assinado sob o pseudônimo de Allan Kardec, Rivail publicaria mais quatro volumes: O livro dos médiuns ou guia dos médiuns e dos evocadores, em janeiro de 1861; O evangelho segundo o espiritismo, em abril de 1864; O céu e o inferno ou a justiça divina segundo o espiritismo, em agosto de 1865 e A gênese, os milagres e as predições em janeiro de 1868. Além desses volumes, sempre sob o pseudônimo de Allan Kardec para sua produção espírita, o sistematizador do espiritismo francês publicou de janeiro de 1858 até 1869, ano de seu falecimento, números mensais da Revista Espirita (KARDEC, 1999), jornal de estudos psicológicos.

O conjunto dessa produção inaugurada a partir de abril de 1857 instaura no tempo e no espaço o imaginário espírita. Em As estruturas antropológicas do imaginário, o pesquisador francês Gilbert Durand (2012, p. 18) conceitua e define o imaginário como sendo "o conjunto das imagens e relações de imagens que constitui o capital pensado do bomo sapiens [...]". Nesta perspectiva, Allan Kardec (2013, p. 13) destaca o espiritismo da massa crítica dos fenômenos espirituais conhecidos sob a rubrica geral de espiritualismo a partir da taxonomia que apresenta no pórtico de O livro dos espíritos: "Para se designarem coisas novas são precisos termos novos. Como especialidade, O livro dos espíritos contém a Doutrina Espírita; como generalidade, prende-se à doutrina espiritualista, [...]".

A definição taxonômica do espiritismo em relação ao espiritualismo se mostra, na prática, bastante significativa do ponto de vista epistemológico. Ela estabelece uma espécie de horizonte de eventos entre o que pertenceria ao campo do espiritismo propriamente considerado e o espiritualismo. No limiar entre ambos, parece haver uma zona de compartilhamento instaurada pelos eventos de natureza mediúnica que dizem respeito tanto ao espiritualismo quanto ao espiritismo. O imaginário literário, considerando-se a definição durandiana (DURAND, 2012, p. 18), espelha singularmente a constituição dos imaginários espírita e espiritualista.

Assim, o espiritismo como imaginário já aparece num grande clássico da literatura universal Oitocentista com toda a carga do fenômeno mediúnico e suas possibilidades exegéticas através da escrita canônica de Fiódor Dostoiévski em Os irmãos Karamazov. No capítulo "O diabo. A alucinação de Ivã Fiódorovitch", o romancista russo traz o inusitado diálogo entre um dos irmãos Karamazov e o diabo, que se senta à frente de Ivã em sua sala de 
estar, num dia gélido, entabulando uma conversação singular acerca da vida, da religiosidade, da teologia e do ateísmo. Em algum momento do extenso diálogo, o representante infernal vestido como um cavalheiro afirma sobre os inusitados fenômenos espíritas e espiritualistas:

A fé não se impõe. Aliás, neste domínio, as provas, mesmo materiais, são ineficazes. Tomé acreditou porque queria acreditar, não por ter visto o Cristo ressuscitado. Assim, os espíritas... gosto muito deles... imagina que acreditam servir à fé, porque o diabo lhes mostra seus chifres de vez em quando. "É uma prova material da existência do outro mundo". O outro mundo demonstrado materialmente! Que idéia! Enfim, isto provaria a existência do diabo, mas não a de Deus. (DOSTOIÉVSKI, 1970, p. 650).

Publicado em primeira edição no ano de 1879, uma década após a morte de Allan Kardec, o denso romance de Dostoiévski faz referência neste trecho à interpretação corrente por parte de determinados segmentos da Igreja, que viam nas manifestações mediúnicas daquele período a própria manifestação do demônio, conforme o sistematizador do espiritismo registra e analisa ao longo de seu trabalho (KARDEC, 2011, p. 166). A fala do diabo remete, também, a um gênero bastante peculiar de manifestação mediúnica em que os seres sobrenaturais se materializariam diante da assistência e dos experimentadores.

Conhecido como materialização, esse gênero de mediunidade permitiria, através da doação de uma substância denominada ectoplasma, que os seres espirituais se corporificassem, dando azo, portanto, à ironia do diabo doistoievskiano. No clássico literário do século XX, A montanha mágica, Thomas Mann (2000, p. 777) descreve uma sessão mediúnica levada a efeito nas dependências do castelo Berghof, que funcionava como gigantesco e cosmopolita hospital na cidade de Davos-Plat, nos Alpes Suíços. Nesse romance de formação, Mann traz a narrativa em torno do desenvolvimento do jovem Hans Castorp, que acaba tornando-se interno do grande hospital após visitar o primo Joachim Ziemssen, ali internado há muito tempo para o tratamento de uma doença pulmonar.

No decorrer da narrativa, Ziemssen vai a óbito. O primo, no entanto, continua internado, pois sua doença não cedia. Os pacientes do Berghof eram muitos e de várias nacionalidades. A internação costumava ser prolongada. $\mathrm{O}$ entretenimento devia ser levado aos pacientes para a manutenção de um clima mínimo de normalidade. Numa das atividades instituídas para diversão, que consistia em tentar encontrar objetos em dependências contíguas às em que se encontravam os jogadores, uma jovem escocesa, Elly Brand, começou a destacar-se por sua extraordinária habilidade de adivinhação sobre objetos e pessoas. 
Sob suspeita de trapaça, ela revela que sua facilidade resultava do fato de ser médium, sendo orientada por um espírito naquele tipo de atividade. A fictícia Brand, à semelhança das históricas Fox, doava um tipo de energia específica que propiciava a ocorrência de fenômenos mediúnicos de efeitos físicos, dentre os quais a materialização dos espíritos. Em memorável sessão narrada minuciosamente por Thomas Mann, Joachim Ziemssen se materializa à vista de Hans Castorp, causando-lhe um choque consciencial que resultará em sua saída do castelo para lutar na Primeira Grande Guerra. Após extensa descrição do fenômeno, o narrador informa que na cadeira ocupada antes do intervalo da sessão pela médium Elly Brand apareceu sentado Joachim: "com as sombras das faces encovadas e com a barba de guerreiro dos seus últimos dias, essa barba em meio à qual ressaltavam os lábios, cheios e altivos. Recostava-se ao espaldar e tinha uma perna cruzada sobre a outra" (MANN, 2000, p. 777).

Este imaginário mediúnico, que marcou toda uma época desde os eventos relacionados à família Fox, impregnou a verve literária dos grandes mestres das letras. Além de Fiódor Dostoiévski e Thomas Mann, nomes exponenciais e canônicos como Marcel Proust, James Joyce e Guimarães Rosa apresentarão em suas produções magnas o ethos característico das sessões mediúnicas constitutivas do imaginário espiritista.

$\mathrm{Na}$ heptalogia intitulada Em busca do tempo perdido, em seu terceiro volume, intitulado O caminho de Guermantes, o escritor francês Marcel Proust antecipara, de certa forma, a narrativa de Mann em torno da sessão de materialização do espírito de Joachim Ziemssen. Em sua arguta e multifacetada apreciação dos saraus parisienses, o narrador proustiano anota: "Ora, quando encontramos na sociedade alguns orientais que pertencem a este ou àquele grupo racial, parece que estamos em presença de criaturas que a força do espiritismo teria feito aparecer" (PROUST, 2014, p. 228). Na sequência dessa observação, descreve detalhadamente aspectos ligados à fenomenologia mediúnica, mencionando as fotografias de espíritos para ressaltar a excentricidade de determinadas personagens estrangeiras.

Acerca desse fenômeno da materialização literalizado por Thomas Mann, o pesquisador em sociologia da Universidade de São Paulo, Reginaldo Prandi, assinala em seu livro Os mortos e os vivos: uma introdução ao espiritismo, que até a década de 1950 reuniões desse gênero foram comuns no Brasil e se notabilizaram pela grande procura: "Buscava-se fotografar e filmar o chamado 'ectoplasma' e os resultados eram mostrados nos jornais, revistas e televisão” (PRANDI, 2012, p. 60). Em seguida a estas palavras, informa que o ectoplasma era "uma substância fluídica, esbranquiçada, de aparência 
diáfana, sutil, expelida pelo corpo de um médium através da boca, dos ouvidos e das narinas, produzindo manchas e formas materializadas do espírito" (PRANDI, 2012, p. 63).

Segundo Prandi (2012, p. 63), a partir da segunda metade do século passado a materialização mediúnica foi conhecendo um certo ostracismo, passando a vigorar a partir de então a perspectiva literária e religiosa do espiritismo, sobretudo decorrente da atuação mediúnica de Francisco Cândido Xavier, que teria escrito ao influxo dos espíritos pouco mais de quatrocentos livros. De maneira curiosa, a literatura canônica e laica em relação ao espiritismo parece ter acompanhado a transição da fenomênica da materialização para a literariedade. No Brasil, João Guimarães Rosa publicava em 1956 uma das mais importantes obras da historiografia literária brasileira, o livro Grande sertão: veredas.

No romance rosiano, o jagunço Riobaldo Tartarana vivencia o drama de haver feito um pacto com o diabo, sem ter a certeza de que o representante do mal tenha comparecido e confirmado o sinistro acordo. Diante desse drama consciencial, Tartarana se apoia no conhecimento espírita de seu compadre Quelemém, "seguidor da doutrina de Cardéque" (ROSA, 1994, p. 10). O diabo é o homem em evolução, em travessia (1994, p. 874).

Em O nascimento do purgatório, o historiador Jacques Le Goff (2017, p. 25) apresenta a narrativa histórica de construção do purgatório católico numa documentalidade remissiva ao ethos do imaginário espírita em sua prática mediúnica e doutrinária (KARDEC, 2011, p. 63), cujo arcabouço doutrinário sustenta que o purgatório é a própria existência terrena com todos os seus percalços, lutas e sofrimentos que marcam e definem a existência terrena. Dentre as inúmeras modalidades de sofrimento humano, a doença é, sem dúvida, uma das que mais afeta a qualidade de vida de todos.

Quando alguma patologia atinge a dimensão de pandemia evoca no imaginário coletivo o horror generalizado. $\mathrm{O}$ atual contexto de pandemia do Covid-19 parece ter saltado das páginas bíblicas para os dias presentes. $\mathrm{Na}$ seção subsequente, buscamos no imaginário espírita em desdobramento no tempo e no espaço uma abordagem em torno da pandemia virótica que assola a humanidade no presente ano de 2020. Em termos de literatura espírita, o que alguma(s) das 1.019 questões apresentadas por Allan Kardec aos habitantes do além teriam a dizer sobre o atual contexto pandêmico? $\mathrm{O}$ que o próprio Allan Kardec teria dito?

Embora o grosso da obra se componha da resposta dos espíritos, Rival-Kardec assinou diversos comentários às respostas espirituais. Nas páginas subsequentes, apresentaremos a palavra dos textos fundantes do kardecismo 
e seus desdobramentos no tempo e no espaço para problemas como o da atual pandemia que atinge em cheio a humanidade no corrente ano.

\section{A literatur fundadora kardequiana e a pandemia do Covid-19}

O espiritismo surge no contexto do zeitgeist espiritualista do século XIX, conforme apresentamos na seção anterior. Hipolyte León Denizard Rivail, vulgo Allan Kardec, entra em contato com os estranhos fenômenos e passa a estudá-los meticulosamente, submetendo as manifestações inteligentes a uma abordagem empirista e racionalista. Possuía ele extraordinário senso pedagógico, até mesmo em função de sua atividade profissional como professor. A historiadora Mary del Priore traça o perfil do sistematizador do espiritismo como sendo um homem dedicado aos estudos. Educado na Suíça (PRIORE, 2014, p. 39): "Falava várias línguas, lecionava diferentes matérias e era tradutor de inglês, alemão e holandês".

O livro dos espíritos, obra que resulta de sua participação nas sessões mediúnicas que ocorriam em profusão na segunda metade do Oitocentismo europeu, reflete essa idiossincrasia. O milhar de perguntas elaboradas por Kardec-Rivail se divide pelos mais diversos temas, que buscam contemplar os mais abrangentes assuntos que, todavia, encadeiam-se meticulosamente. $\mathrm{O}$ toque teológico, conducente à perspectiva de religiosidade que o espiritismo assumiria ao longo do tempo, surge na primeira pergunta feita ao mundo espiritual: "Que é Deus?” (KARDEC, 2013, p. 55). À resposta se seguem outras questões que buscam desdobrá-la.

Reginaldo Prandi, resume a doutrina kardequiana nos seguintes termos:

Segundo Kardec, a comunicação com os espíritos dos mortos, ou desencarnados, não somente é possível, mas desejável. A vida na Terra nada mais é que um pequeno e transitório momento na trajetória do espírito, de modo que a compreensão do ser humano e de tudo que ele faz aqui só é possível se se levar em conta seu passado constituído de outras vidas e seu futuro muito além da morte. Todos os que vivem na Terra nada mais são que espíritos reencarnados, que podem ter habitado e ainda irão habitar diferentes mundos em suas diferentes encarnações. (PRANDI, 2012, p. 39).

Na textualidade fundadora do espiritismo, Allan Kardec elaborou as perguntas de número 728 a 741 em O livro dos espíritos, que estão inseridas no sexto capítulo da terceira parte, intitulado "Da lei de destruição", que são remissivas ao contexto da pandemia de Covid-19 que no momento representa um grande sofrimento coletivo globalizado. Nesse capítulo, são tratados temas como pestes, guerras, assassínios, crueldade e pena de morte. $\mathrm{Na}$ 
pergunta 737, que abre o tópico dos flagelos destruidores, Kardec pergunta: "Com que fim fere Deus a Humanidade por meio de flagelos destruidores?" (KARDEC, 2013, p. 337). As almas do além respondem que é para fazê-la progredir mais depressa:

Já não dissemos ser a destruição uma necessidade para a regeneração moral dos Espíritos, que, em cada nova existência, sobem um degrau na escala do aperfeiçoamento? Preciso é que se veja o objetivo, para que os resultados possam ser apreciados. Somente do vosso ponto de vista pessoal os apreciais; daí vem que os qualificais de flagelos, por efeito do prejuízo que vos causam. Essas subversões, porém, são frequentemente necessárias para que mais pronto se dê o advento de uma melhor ordem de coisas e para que se realize em alguns anos o que teria exigido muitos séculos. (KARDEC, 2013, p. 337).

As demais perguntas desdobram esse tópico. No questionamento seguinte é perguntado se Deus não poderia empregar outros meios que não os flagelos destruidores para que a humanidade evoluísse mais rapidamente (KARDEC, 2013, p. 337). A resposta diz que todos os dias Deus emprega esses meios, pois deu ao homem a capacidade de progredir pelo conhecimento do bem e do mal; mas esses meios não são aproveitados pelos homens: "Necessário, portanto, se torna que seja castigado no seu orgulho e que se lhe faça sentir a sua fraqueza" (KARDEC, 2013, p. 337).

Kardec não se dá por satisfeito e observa aos seres espirituais que nesses flagelos destruidores tanto sucumbem o homem de bem quanto os perversos: "Será justo isso?" (2013, p. 337). Respondem os espíritos que a vida do corpo é bem pouca coisa, representando um século um relâmpago diante da eternidade: "Logo, nada são os sofrimentos de alguns dias ou de alguns meses, de que tanto vos queixais. Representam um ensino que se vos dá e que vos servirá no futuro" (KARDEC, 2013, p. 337). Ao comentar essas e outras observações que os espíritos fazem sobre o tema, Rivail-Kardec menciona que a peste, a fome, as inundações e as intempéries que impedem a terra de produzir são independentes do homem, observando que ele tem encontrado na Ciência todo um aparato que o permite minorar as condições desses flagelos (KARDEC, 2013, p. 339).

Allan Kardec elenca, dentre os flagelos destruidores, a peste, nome genérico para doenças que se alastram descontroladamente, como é o caso da pandemia de Covid-19. Cerca de seis décadas após suas palavras, a humanidade vivenciaria a sua mais devastadora peste: a epidemia da gripe espanhola, que dizimou a vida de milhões de pessoas em todo o globo. A atual pandemia do vírus Covid-19 surge praticamente um século depois da gripe espanhola e se insere nesse contexto de flagelo universal. Das consi- 
derações de Kardec-Rivail à fala dos espíritos acerca da temática, ressalta a importância da técnica e da ciência humana no combate a todos os tipos de flagelos destruidores. A atual busca por uma vacina representa bem o que o sistematizador do espiritismo discorre acerca da utilização da ciência para minorar os problemas característicos de uma pandemia como a que se vivencia atualmente.

Neste contexto de uma interação entre o plano material e a espiritualidade advogada pelo espiritismo, uma dúvida se apresentaria naturalmente. Se os espíritos se comunicam através dos médiuns, não poderiam ser interrogados sobre a aquisição de vacinas e descobertas científicas que minorassem problemas como uma pandemia de Covid-19? Em O livro dos médiuns ou guia dos médiuns e dos evocadores, no tópico 294, que trata da possível intervenção espiritual nas invenções e descobertas, questiona Kardec se os espíritos podem guiar o homem nas pesquisas científicas e nas descobertas. Responderam eles que a ciência deve ser fruto do esforço humano mediante o trabalho da inteligência e o esforço próprio:

Que mérito teria, se apenas precisasse interrogar os Espíritos para saber tudo? A esse preço, qualquer imbecil poderia tornar-se sábio. O mesmo se dá com as invenções e descobertas da indústria. Depois, uma outra consideração, é que cada coisa deve vir a seu tempo e, quando as ideias estão maduras para recebê-la; se o homem tivesse este poder, subverteria a ordem das coisas, fazendo que aparecessem os frutos, antes da estação própria. (KARDEC, 2010, p. 367).

Para dirimir qualquer dúvida, Rivail-Kardec pergunta se então os sábios e os cientistas nunca seriam assistidos pela espiritualidade em suas tarefas de pesquisas. A resposta é bastante incisiva e pode ser pensada no contexto da pandemia de Covid-19 e o gigantesco esforço que a comunidade científica mundial tem realizado em busca de vacinas e tratamentos eficazes contra o coronavírus:

Oh! Isto é muito diferente. Quando chega o tempo de uma descoberta, os Espíritos encarregados de lhe dirigir a marcha, procuram o homem capaz de levá-la a bom termo e lhe inspiram as ideias necessárias, de maneira a lhe deixarem todo o mérito, porquanto estas ideias, é preciso que ele as elabore e as execute. O mesmo acontece com todos os grandes trabalhos da inteligência humana. Os Espíritos deixam cada homem na sua esfera de ação; daquele que só está apto para cavar a terra, não farão o depositário dos segredos de Deus; mas saberão tirar da obscuridade o homem capaz de secundar seus desígnios. Não vos deixeis, portanto, arrastar pela curiosidade ou ambição num caminho que não corresponde ao objetivo do Espiritismo e que vos levaria às mais ridículas mistificações. (KARDEC, 2010, p. 367). 
A estas palavras, Kardec junta a observação sobre casos ridículos de que teve conhecimento sobre pessoas que tentaram obter dos espíritos as mais bizarras panaceias para mazelas como calvície, calos e outras problemáticas ligadas à precariedade orgânica da vida humana (KARDEC, 2010, p. 367). No conjunto da sua textualidade fundadora, o sistematizador do espiritismo estabelecerá como norma doutrinária a necessidade de caminhar com as descobertas científicas que tenham atingido o status de verdade prática comprovada, uma vez que o espiritismo abrangeria "todos os ramos da economia social, aos quais presta o apoio de suas próprias descobertas [...]" (KARDEC, 1999, p. 16).

\section{O desdobramento da textualidade kardequiana no Brasil e o enfrentamento da Covid-19}

Em seu trabalho de caráter sociológico, Reginaldo Prandi registra o surgimento e a popularização do espiritismo no Brasil. Segundo o autor, um dos motivos pelos quais os brasileiros tiveram a sua atenção voltada para a doutrina espírita se deve ao fato de a França representar a grande influência cultural para o país no século XIX: "As poucas livrarias brasileiras vendiam, sobretudo, livros publicados na França, e até obras escritas por brasileiros eram editadas naquele país. [...] O sucesso das ideias de Kardec no país foi imediato" (PRANDI, 2012, p. 47).

Em seu estudo, Prandi mapeia as origens institucionais do espiritismo, que no Brasil vai assumir-se de forma prioritária como religião (PRANDI, 2012, p. 51). Após referenciar as diversas instituições de estudos espíritas que foram fundadas, mas que tiveram vida breve por diversos motivos, registra o autor de Os mortos e os vivos: uma introducãa ao espiritismo o surgimento da instituição que ainda hoje lidera grande parte do espiritismo como movimento de religiosidade, a Federação Espírita Brasileira, que surgiu em 1884 no Rio de Janeiro para reunir outros grupos dispersos (PRANDI, 2012, p. 53).

Após uma fase inicial de intensa preocupação com as curas mediúnicas e os fenômenos de materialização (PRANDI, 2012, p. 63), surge a figura de Francisco Cândido Xavier, que levará a mediunidade espírita para um patamar de intensa produção literária na dupla perspectiva germânica da literatur e da dichtung, o que influenciará decisivamente os rumos do espiritismo no Brasil do século XX até os dias atuais. A Federação Espírita Brasileira será a casa editora de significativa parcela da produção mediúnica de Chico Xavier, que em muitos aspectos reforçam a necessidade do respeito à orientação da ciência terrena, em considerações homológicas às de Rivail-Kardec (PRANDI, 2012, p. 67). 
A produção mediúnica xavieriana conta com números expressivos. São pouco mais de quatro centenas de livros publicados. Dessa parcela, constam 13 obras que compõem a coleção "A vida no mundo espiritual", de autoria de um espírito que fora médico na terra e que adotou o pseudônimo de André Luiz (PRANDI, 2012, p. 67). A parceria Chico Xavier/André Luiz já rendeu ao mineiro de Pedro Leopoldo a condição de objeto de estudo de um artigo científico em uma das mais prestigiadas revistas da área de endocrinologia do mundo. Escrito por três médicos brasileiros, o paper trata das antecipações científicas que o médico desencarnado teria trazido no campo da endocrinologia acerca da glândula pineal pela mediunidade de Xavier (LUCCHETTI, 2013).

Se o espiritismo não desenvolveu o seu aspecto científico, firmando-se no Brasil como religião, conforme sustenta Reginaldo Prandi (2012, p. 623), nas últimas décadas têm se desenvolvido no âmbito desse movimento instituições específicas que buscam correlacionar os aspectos doutrinários de Kardec e seus continuadores com atividades próprias das ciências acadêmicas, numa mediação feita por pesquisadores que atuam no limiar entre a academia e o espiritismo. Uma dessas instituições é Associação Médico-Espírita do Brasil, que foi criada no ano de 1995.

A AME-Brasil, sigla com que se tornou conhecida, congrega, naturalmente, profissionais médicos que compartilham das crenças espíritas. Essa instituição, por sua própria natureza, torna-se voz importante no âmbito do movimento espírita brasileiro, sendo ouvida em suas deliberações em torno de problemas alusivos à saúde em conexão com a espiritualidade. Na pandemia de Covid-19, a Federação Espírita Brasileira postou em seu sítio na internet nota de esclarecimento da AME-Brasil sobre a importância de atender aos ditames científicos para o enfrentamento da crise sanitária (FEDERAÇÃO ESPÍRITA BRASILEIRA, 2020).

A nota da Associação Médico-Espírita do Brasil replicada pela Federação Espírita Brasileira, datada de 13 de março de 2020, situa a Covid-19 no contexto médico e espiritual e apresenta propostas que se alinham com a cientificidade que deve ser inerente ao momento pandêmico vivido pela comunidade mundial. Após apresentar o contexto médico, a instituição sugere medidas de contenção, como o cancelamento de todas as atividades doutrinária presenciais em atendimento às exigências sanitárias e incentiva a realização de atividades tecnológicas virtuais para as práticas de reuniões doutrinárias.

A nota informa, dentre outros aspectos:

A evolução da pandemia de Coronavírus (COVID-19), com ocorrência em vários países e se disseminando rapidamente, torna essencial a participação de toda a nossa 
sociedade nas medidas necessárias para sua prevenção e controle. Apesar de se tratar de um novo vírus, o conhecimento acumulado até o momento, a partir dos milhares de casos em outras regiões, tem permitido que nosso país desenvolva planos de ação procurando reduzir os danos desta pandemia, já considerada uma emergência de saúde pública. Mas será necessária a mobilização e participação de todos. (FEDERAÇÃO ESPÍRITA BRASILEIRA, 2020).

Após informar, recomenda medidas sanitárias dentre as quais enunciamos quatro:

1. Seguir as recomendações dos órgãos oficiais, Ministério da Saúde do Brasil e Organização Mundial da Saúde, quanto aos comportamentos adequados tais como "etiqueta respiratória" (tossir ou espirrar no próprio braço ou dento da camisa), higienização frequente das mãos com álcool gel a 70\% ou com água e sabão e evitar contato das mãos com as mucosas da boca, nariz e olhos. Pessoas com sintomas respiratórios devem procurar o atendimento médico o mais breve possível e colaborar com o isolamento domiciliar até ordem médica.

2. Devido à grande dimensão territorial do Brasil e a pluralidade de cenários, as medidas de contenção podem variar conforme a localidade. Assim, é importante estar atento às recomendações dos estados e municípios, que podem mudar durante o período de pandemia. [...]

4. Trabalhos de atendimento espiritual abertos ao público podem ser realizados por atendimento à distância (por exemplo, passe a distância), através do trabalho de irradiações, com a formação de correntes de vibração, através da prece, em favor de toda a comunidade mundial, brasileira.

[...] 5. Reuniões com grande número de pessoas devem ser evitadas. Para as casas espíritas com recursos disponíveis as atividades virtuais são preferíveis durante o período da pandemia (FEDERAÇÃO ESPÍRITA BRASILEIRA, 2020).

A estrutura organizacional do movimento espírita segue majoritariamente a Federação Espírita Brasileira. Os demais estados brasileiros possuem as suas federações locais. Em sua grande maioria, elas são alinhadas com as orientações da Federação Espírita Brasileira, seguindo as normativas estabelecidas por ela. De maneira semelhante à iniciativa nacional, vários estados do Brasil têm criado as suas associações médico-espíritas nos moldes da Associação Médico-Espírita do Brasil. Do texto reproduzido pela Federação Espírita Brasileira como informe inicial sobre o Covid-19, infere-se a propensão de seguir a orientação estabelecida por Kardec nas páginas fundadoras do imaginário espírita na França da segunda metade do século XIX.

\section{Considerações finais}

A história espiritual do século XIX foi marcada pela ocorrência de estranhos fenômenos que deram origem a um imaginário que os enfeixou em um 
sistema doutrinário, o espiritismo. Allan Kardec deu o nome de mediunidade à massa crítica dos eventos sobrenaturais. Os fenômenos mediúnicos tiveram continuidade no tempo e no espaço, florescendo de modo significativo em solo brasileiro graças à influência cultural francesa no século XIX.

Desde o início, a expressão escrita se mostrou fundamental na elaboração da nova doutrina, assim como também em seu desdobramento espaço-temporal. Neste estudo buscamos articular o conceito de literatura em alemão apresentado pelo crítico Antonio Candido para evidenciar como ele foi representativo na construção do imaginário do espiritismo. A partir do que foi pontuado neste estudo, a representação institucional espírita em recorte tem pautado sua atuação na pandemia do Covid-19 conforme as palavras do sistematizador Allan Kardec, numa práxis que tem buscado alinhar-se com a cientificidade que o momento pandêmico exige.

No âmbito de uma pesquisa qualitativa posterior, contudo, permanece em aberto a possibilidade de pesquisas que busquem enfocar se em nível individual houve a mesma aderência dos profitentes do espiritismo durante esse período da pandemia de Covid-19, que já se mostra bastante extenso em face das necessidades de locomoção e trabalho por parte da comunidade global com fins de subsistência.

\section{Referências bibliográficas}

BOIVIN, Patrice. Victor Hugo - o livro das mesas: as sessões espíritas da ilha de Jersey. São Paulo: Três Estrelas, 2018.

CANDIDO, Antonio. O estudo analítico do poema. São Paulo: Humanitas, 1996.

DOSTOIÉVSKI, Fiódor. Os irmãos Karamaz̧ov. São Paulo: Abril Cultural, 1970.

DURAND, Gilbert. As estruturas antropológicas do imaginário. São Paulo: Martins Fontes, 2012.

FEDERAÇÃO ESPÍRITA BRASILEIRA. Disponível em: < https://www.febnet.org.br/ portal/2020/03/13/informe-da-ame-brasil-sobre-o-coronavirus/> [Acesso em 25 jul. 2020].

JAKOBSON, Roman. Lingüistica e comunicação. São Paulo: Cultrix, 2003.

KARDEC, Allan. Revista Espirita, Araras, [Instituto de Difusão Espírita], 1999.

KARDEC, Allan. Obras póstumas. Rio de Janeiro: CELD, 2002.

KARDEC, Allan. O livro dos médiuns ou guia dos médiuns e dos evocadores. Rio de Janeiro: CELD, 2010.

KARDEC, Allan. O céu e o inferno ou a justiça divina segundo o espiritismo. Rio de Janeiro: CELD, 2011.

KARDEC, Allan. O livro dos espíritos. Brasília: FEB, 2013. 
LE GOFF, Jacques. O nascimento do purgatório. Petrópolis: Editora Vozes, 2017.

LUCCHETTI, Giancarlo et al. Historical and cultural aspects of the pineal gland: comparison between the theories provided by Spiritism in the 1940s and the current cientific evidence. Neuroendocrinology Letters, Ano 21, n. 8, p. 745-755, 2013.

MANN, Thomas. A montanha mágica. Rio de Janeiro: Nova Fronteira, 2000.

PRANDI, Reginaldo. Os mortos e os vivos: uma introdução ao espiritismo. São Paulo: Três Estrelas, 2012.

PRIORE, Mary del. A bistória do sobrenatural e do espiritismo. São Paulo: Planeta, 2014.

PROUST, Marcel. Em busca do tempo perdido: o caminho de Guermantes. Rio de Janeiro: Nova Fronteira, 2014.

Submetido em: 22-9-2020

Aceito em: 14-1-2021 